\title{
Production of nanometric particles in radio frequency glow discharges in mixtures of silane and methane
}

\author{
E. Bertran, ${ }^{\text {a) }}$ J. Costa, G. Viera, and R. Q. Zhang \\ Departament de Física Aplicada i Electrònica, Universitat de Barcelona, E08028 Barcelona, \\ Catalonia, Spain
}

(Received 4 October 1995; accepted 15 December 1995)

\begin{abstract}
The formation of silicon particles in rf glow discharges has attracted attention due to their effect as a contaminant during film deposition or etching. However, silicon and silicon alloy powders produced by plasma-enhanced chemical vapor deposition (PECVD) are promising new materials for sintering ceramics, for making nanoscale filters, or for supporting catalytic surfaces. Common characteristics of these powders are their high purity and the easy control of their stoichiometry through the composition of the precursor gas mixture. Plasma parameters also influence their structure. Nanometric powders of silicon-carbon alloys exhibiting microstructural properties such as large hydrogen content and high surface/volume ratio have been produced in a PECVD reactor using mixtures of silane and methane at low pressure $(<1$ Torr) and low frequency square-wave modulated rf power $(13.56 \mathrm{MHz})$. The $a-\mathrm{Si}_{1-x} \mathrm{C}_{x}: \mathrm{H}$ powders were obtained from different precursor gas mixtures, from $\mathrm{R}=0.05$ to $\mathrm{R}=9$, where $\mathrm{R}=\left[\mathrm{SiH}_{4}\right] /\left(\left[\mathrm{SiH}_{4}\right]+\left[\mathrm{CH}_{4}\right]\right)$. The structure of the $a-\mathrm{Si}_{1-x} \mathrm{C}_{x}: \mathrm{H}$ powder was analyzed by several techniques. The particles appeared agglomerated, with a wide size distribution between 5 and $100 \mathrm{~nm}$. The silane/methane gas mixture determined the vibrational features of these powders in the infrared. Silicon-hydrogen groups were present for every gas composition, whereas carbon-hydrogen and silicon-carbon bonds appeared in methane-rich mixtures $(\mathrm{R}<0.6)$. The thermal desorption of hydrogen revealed two main evolutions at about 375 and $660{ }^{\circ} \mathrm{C}$ that were ascribed to hydrogen bonded to silicon and carbon, respectively. The estimated hydrogen atom concentration in the sample was about 50\%. (C) 1996 American Vacuum Society.
\end{abstract}

\section{INTRODUCTION}

The formation of particles in plasma-enhanced chemical vapor deposition (PECVD) processes is the origin of contamination during thin-film deposition or etching. Many recent reports deal with the generation dynamics of these particles and the possibility of their removal. ${ }^{1,2}$ Nevertheless, due to their nanometric size and their controllable microstructure the production of powder merits further study as it might be an interesting source of raw material for sintering ceramics, nanoscale filters, or support for catalytic surfaces. The production of silicon particles in PECVD processes has already been studied and related to the plasma parameters. ${ }^{3}$ Moreover, their structure has been analyzed. ${ }^{4}$ The special characteristics of silicon powders produced by PECVD were the nanometer size, and hence the high surface/volume ratio, and the high hydrogen content. ${ }^{3,4}$ In addition, these silicon particles presented interesting and unusual photoluminescent properties. ${ }^{5}$ The influence of thermal and laser annealing on both the hydrogen bonding and the luminescent properties has also been described. ${ }^{3,4,6}$

By PECVD, it is also possible to produce alloys using a mixture of precursor gases and to control their microstructure through the plasma parameters (pressure, gas flow, power density, and power modulation). A review of other preparation methods and properties of ultrafine powders of high melting point compounds can be found in Ref. 7. In

a)Author to whom correspondence should be addressed; electronic mail: ebertran@electra.fae.ub.es
PECVD processes, the square-wave modulation (SQWM) of the rf power applied to the discharge is commonly used to allow the negative species electrostatically confined in the plasma to leave it. The effect of SQWM of the plasma on the film microstructure has been extensively reported. ${ }^{8-12}$

In this article we present a preliminary study of the production of $a-\mathrm{Si}_{1-x} \mathrm{C}_{x}: \mathrm{H}$ particles in glow discharges of silane and methane gas mixtures. First, elemental analysis (EA) has provided the carbon and hydrogen concentration on the $a-\mathrm{Si}_{1-x} \mathrm{C}_{x}: \mathrm{H}$ powders produced at different silane/ methane mixtures. The particle size and agglomeration was determined by transmission electron microscope (TEM). High-resolution images allowed us to determine the amorphous structure of these particles. By Fourier transform infrared (FTIR) spectroscopy, Raman spectroscopy, and thermal desorption spectrometry of hydrogen (TDSH), the vibrational properties and hydrogen bonding were studied, and the spontaneous oxidation of the powder was revealed.

\section{EXPERIMENT}

The $a-\mathrm{Si}_{1-x} \mathrm{C}_{x}: \mathrm{H}$ powders were produced from different silane-methane gas mixtures in a capacitive coupled plasma reactor $^{13}$ by the PECVD technique. The PECVD process used an rf power supply which could be modulated by a square-wave signal at different frequencies and periods of duty cycle.

The reactor was kept at room temperature and the plasma was modulated at low frequency with $50 \%$ duty cycle. The flow rates of $\mathrm{SiH}_{4}$ and $\mathrm{CH}_{4}$ into the reaction chamber were 
changed by means of mass flow controllers, whereas the total pressure was kept constant by a pressure controller. The total gas flow rate was in the range $20-40$ standard cubic centimeters per minute $(\mathrm{sccm})$, and the relative fraction of silane, $\mathrm{R}=\left[\mathrm{SiH}_{4}\right] /\left(\left[\mathrm{SiH}_{4}\right]+\left[\mathrm{CH}_{4}\right]\right.$ was varied from $\mathrm{R}=0.05$ to $\mathrm{R}=0.9$. The plasma process was monitored by a capacitive voltage probe to determine the rf potential, $V_{\mathrm{rf}}$. The dissipated power in the discharge ( $48 \mathrm{~W}$ in all cases, which corresponds to a power density of $120 \mathrm{~mW} / \mathrm{cm}^{2}$ ) was determined via the substractive method. ${ }^{14}$

The optical transmittance of the particles, diluted in ethanol to obtain a deagglomerated homogeneous sample, was measured by a multichannel analyzer working in the ultraviolet-visible (UV-VIS) range $(300-800 \mathrm{~nm})$. The electron microscopy images were obtained with a Philips CM30 microscope operating at $300 \mathrm{kV}$. Raman backscattering measurements were performed with the $514 \mathrm{~nm}$ line of an $\mathrm{Ar}$ laser and a triple monochromator followed by an array of detectors. The infrared transmission spectra in the range between 400 and $4000 \mathrm{~cm}^{-1}$ were obtained in a Nicolet 5ZDX Fourier transform spectrophotometer. The thermal desorption spectrometry of hydrogen was performed in a vacuum chamber connected to a quadrupolar mass spectrometer. The sample was heated to $800{ }^{\circ} \mathrm{C}$ by an oven controlled by a computer that generated a temperature ramp of $20^{\circ} \mathrm{C} / \mathrm{min}$.

\section{RESULTS AND DISCUSSION}

$a-\mathrm{Si}_{1-x} \mathrm{C}_{x}: \mathrm{H}$ powders have been produced at room temperature and a fixed value of $\mathrm{rf}$ power dissipated in the plasma of $48 \mathrm{~W}$. Two series of samples were prepared at two pressures, using different $\mathrm{SiH}_{4}$ to $\mathrm{CH}_{4}$ gas ratios. The conditions corresponding to the first series were: $80 \mathrm{~Pa}$ of total pressure and $100 \mathrm{mHz}$ of SQWM frequency. The gas ratios tested $\mathrm{R}$ were $0.1,0.25,0.55$, and 0.9 (where $\mathrm{R}$ is defined as $\left.\left[\mathrm{SiH}_{4}\right] /\left[\mathrm{SiH}_{4}\right]+\left[\mathrm{CH}_{4}\right]\right)$. The second series of samples was produced at $40 \mathrm{~Pa}$ of total pressure and using gas ratios $\mathrm{R}$ of $0.05,0.2,0.3,0.4$, and 0.6 . The $\mathrm{rf}$ power modulation frequency was $200 \mathrm{mHz}$.

The dependence of the carbon atom concentration for the second series, determined by EA, on the gas mixture in the plasma is presented in Fig. 1. The hydrogen concentration was about $50 \%$ and it did not depend on the precursor gas mixture.

Figure 2(a) shows the peak to peak rf voltage during a period of plasma on for the discharges of the second series. First, when the plasma is lit, there is a narrow voltage peak that takes a few ms. After reaching the maximum of this peak, the rf voltage decreased smoothly to a stable value. The relative height of this peak scales with the silane concentration, as shown in Fig. 2(b). In SQWM discharges these transient features during plasma on periods have been described for both the electron density ${ }^{9}$ and the optical emission of the plasma. ${ }^{15}$ It is generally accepted that some electron losses are the origin of this transient phenomenon. Although some authors proposed that these electron losses may be due to dissociative attachment involving negative radicals, ${ }^{9}$ in a dusty plasma the highest losses may be due to

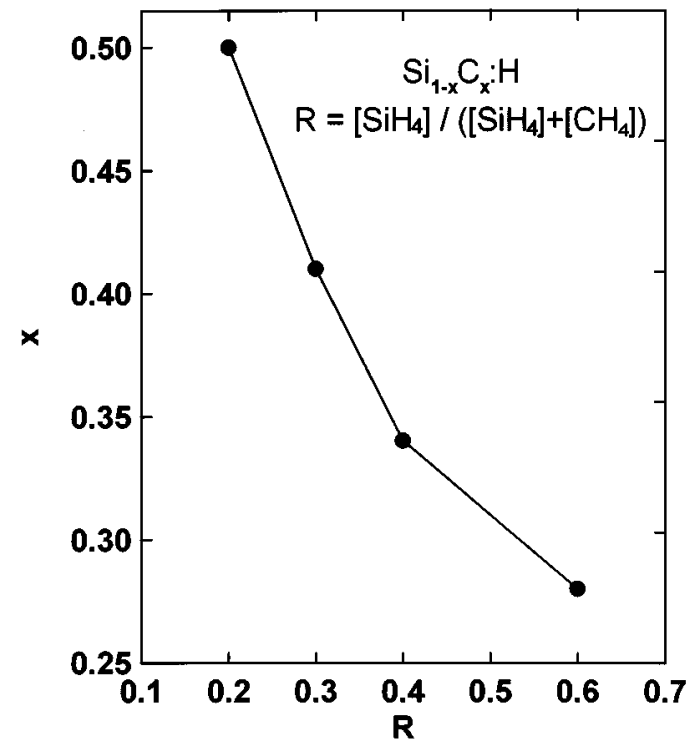

FIG. 1. Dependence of the carbon concentration $x$ on the precursor gas mixture $\mathrm{R} . \mathrm{R}=\left[\mathrm{SiH}_{4}\right] /\left(\left[\mathrm{SiH}_{4}\right]+\left[\mathrm{CH}_{4}\right]\right)$ for the second series of powders.
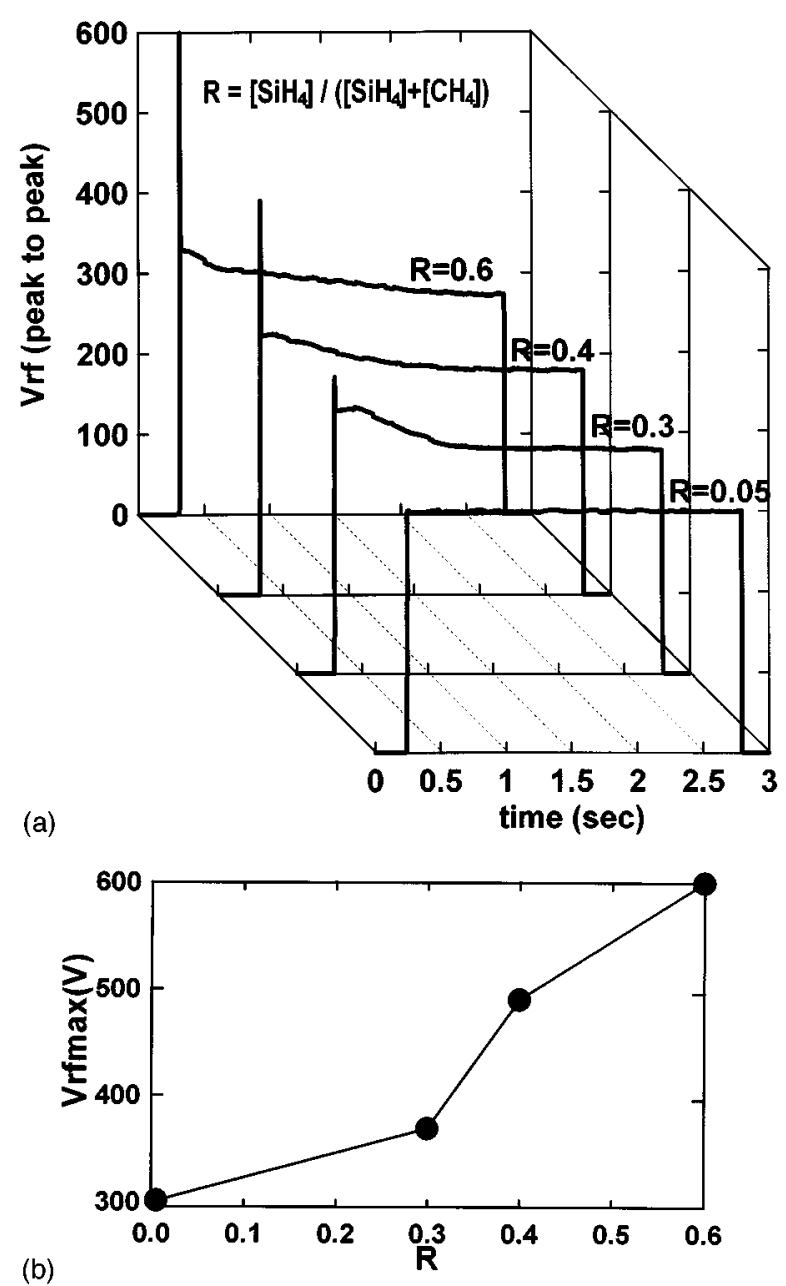

FIG. 2. (a) Radio-frequency peak-to-peak voltage during a plasma-on period. (b) Dependence of the voltage peak on the silane concentration. 


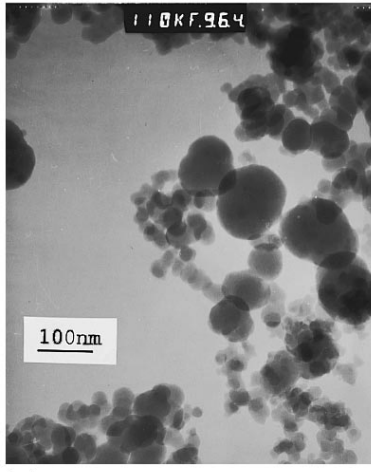

(a)

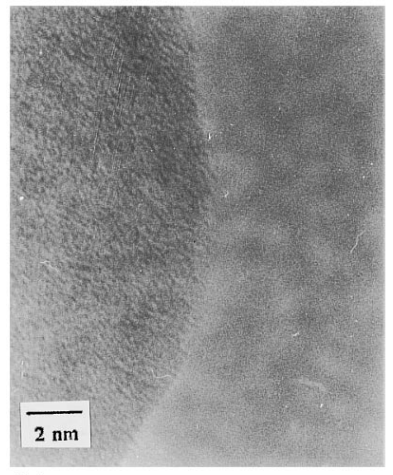

(b)
FIG. 3. Representative TEM micrographs of $a-\mathrm{Si}_{1-x} \mathrm{C}_{x}: \mathrm{H}$ particles. (a) The diameter of the particles was less than $100 \mathrm{~nm}(5-15 \mathrm{~nm}$ for most of them). (b) High-resolution TEM that does not show any ordered domain.

the particles that act as traps of negative charges. This explains why the height of this peak scales with the concentration of silane (we observed that, at low silane concentrations, the formation of powders is reduced dramatically).

Figure 3(a) shows a representative TEM image of the samples obtained. All the TEM micrographs of samples produced in different discharges showed similar features, i.e., spherical particles with diameters below $100 \mathrm{~nm}$ with a wide size distribution. Most of them showed diameters around 5-10 nm. The particles always appeared stuck to each other, forming agglomerates, some of them with worm shapes. The electron diffraction patterns and the high-resolution [see Fig. 3(b)] images indicated that these particles are amorphous.

Figure 4 shows the transmittance spectra corresponding to the first series of $a-\mathrm{Si}_{1-x} \mathrm{C}_{x}: \mathrm{H}$ powders. All the spectra showed a soft absorption front with a gradual shift to higher energies as Si content decreased. The energy gap $E_{g}$ can be estimated from the absorption coefficient $\alpha$ spectra and using the Tauc expression, ${ }^{16}$

$$
\epsilon_{2}^{1 / 2} E=B\left(E-E_{g}\right),
$$

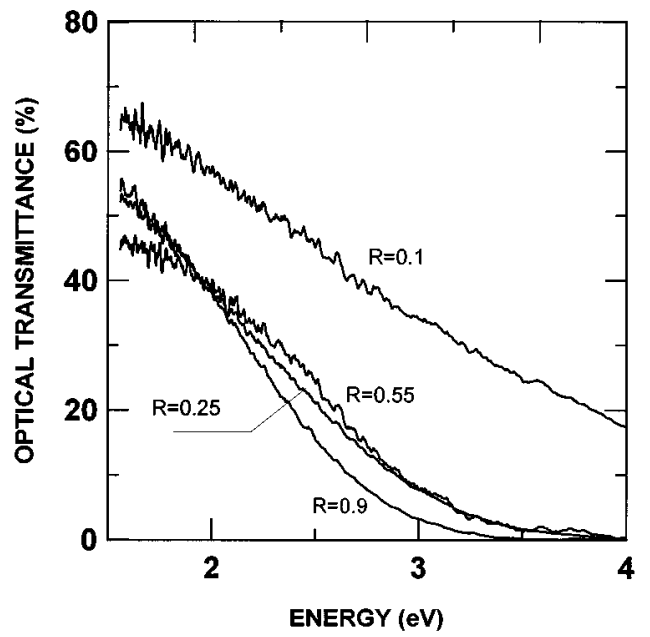

FIG. 4. Optical transmittance of the first series of $a-\mathrm{Si}_{1-x} \mathrm{C}_{x}: \mathrm{H}$.

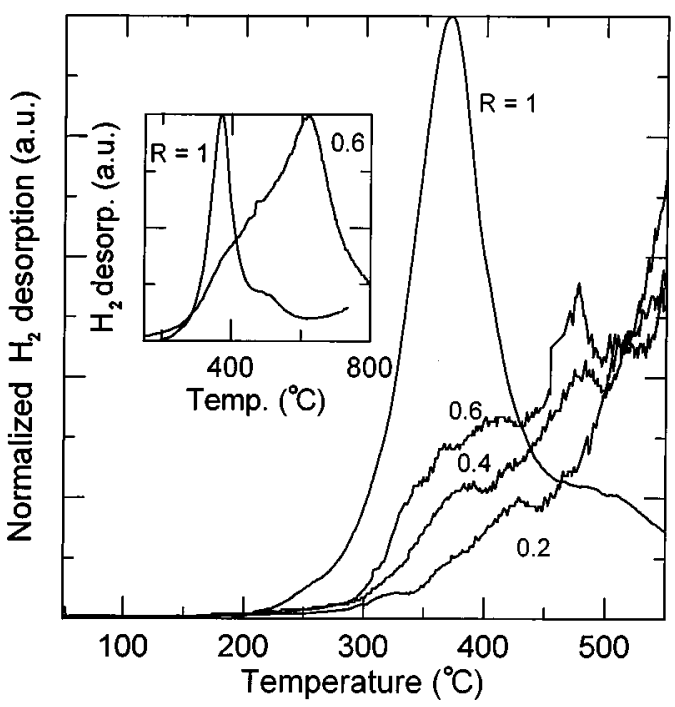

FIG. 5. TDSH spectra for samples with different carbon concentration. The low-temperature evolution depends on the carbon concentration in the powder samples. The inset shows the complete TDSH of pure silicon and of $a-\mathrm{Si}_{1-x} \mathrm{C}_{x}: \mathrm{H}$ produced in a discharge with $\mathrm{R}=0.6$.

where $\epsilon_{2}$ is the imaginary part of the dielectric function, $E$ is the photon energy, and $B$ a constant. The estimated $E_{g}$ values range between $2 \mathrm{eV}$ for the highest silicon content $(\mathrm{R}=0.9)$ and $2.5 \mathrm{eV}$ for $\mathrm{R}=0.25$. The $E_{g}$ of the sample grown at $\mathrm{R}=0.1$ has been estimated to be higher than $3 \mathrm{eV}$. This result agrees with the observed variation of colors of $a-\mathrm{Si}_{1-x} \mathrm{C}_{x}: \mathrm{H}$ powder samples with $x$, which gradually changes from deep yellow to transparent as silicon content decreases. It should be noted that the $E_{g}$ of the powder samples was higher than the $E_{g}$ of thin films with the same carbon concentration. ${ }^{17}$ The origin of the energy gap widening might be related to quantum confinement in the smallest particles.

The experiments of hydrogen desorption under thermal annealing revealed significant differences between the hydrogen evolution in pure silicon particles and in $a-\mathrm{Si}_{1-x} \mathrm{C}_{x}: \mathrm{H}$ particles. The inset of Fig. 5 shows that the main evolution of the TDSH spectrum for pure silicon powders started at around $200{ }^{\circ} \mathrm{C}$ and reached its maximum near $375^{\circ} \mathrm{C}$. Nevertheless, the evolution of hydrogen from the sample $a-\mathrm{Si}_{1-x} \mathrm{C}_{x}: \mathrm{H} \quad(\mathrm{R}=0.6)$ started at approximately the same temperature, and the maximum desorbed hydrogen appeared at $660^{\circ} \mathrm{C}$. As seen in the Fig. 5, a relatively weak evolution around $375^{\circ} \mathrm{C}$ was also present. The relative contribution of this peak directly depended in the silicon concentration on the sample. This dependence, as well as the predominance of hydrogen-carbon bonds over silicon-hydrogen bonds, is related to the fact that the $\mathrm{C}-\mathrm{H}$ bond has a higher heat of formation than the $\mathrm{Si}-\mathrm{H}$ bond. ${ }^{18}$

Figure 6 shows the infrared (IR) spectra corresponding to the first series of $a-\mathrm{Si}_{1-x} \mathrm{C}_{x}: \mathrm{H}$ powders which evidenced the usual features of hydrogenated silicon-carbon alloys thin films. ${ }^{18}$ Silicon-hydrogen related peaks appeared in all samples. The bond-wagging mode appeared at $650 \mathrm{~cm}^{-1}$ in the silicon-rich samples. The presence of $\mathrm{SiH}_{2}$ radicals and 


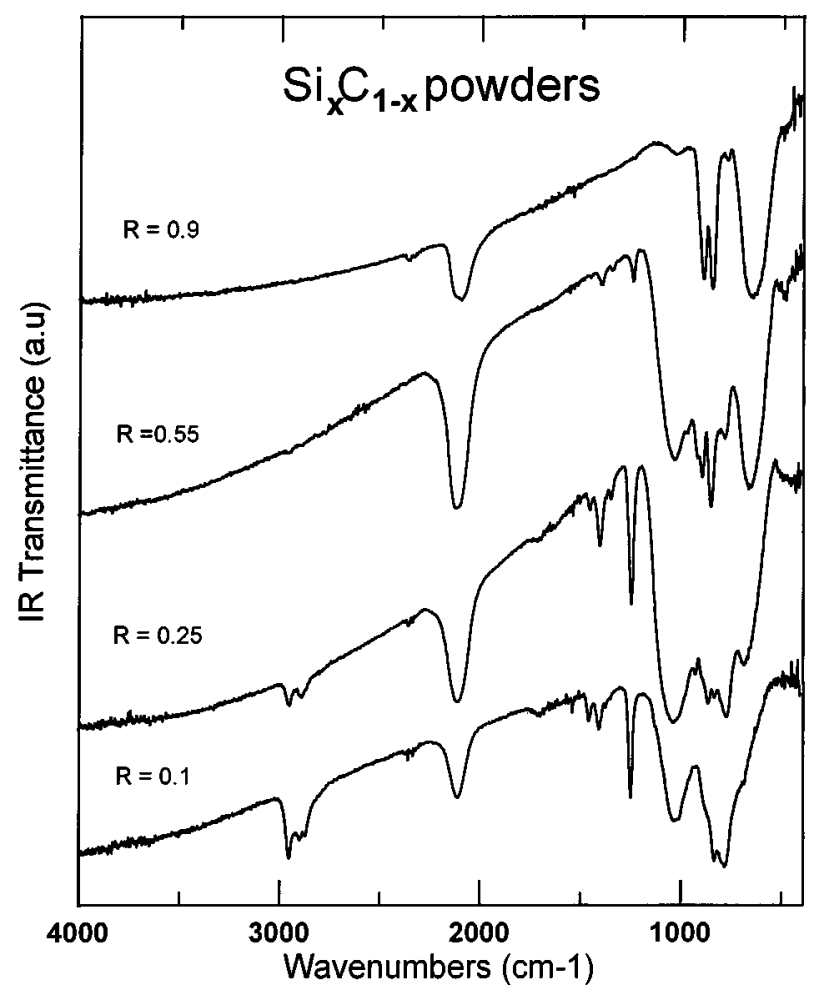

FIG. 6. IR transmission spectra of the first series of $a-\mathrm{Si}_{1-x} \mathrm{C}_{x}: \mathrm{H}$ powder samples.

polymeric groups, $\left(\mathrm{SiH}_{2}\right)_{n}$ was shown in the absorption doublet, due to bending modes, between 800 and $900 \mathrm{~cm}^{-1}$. As Fig. 7 reveals, both the wagging and bending bands decrease with the carbon concentration. This tendency is due to the fact that hydrogen is preferentially bonded to carbon rather than to silicon atoms, in good agreement with the TDSH results. The stretching band of silicon-hydrogen modes appeared at $2100 \mathrm{~cm}^{-1}$ regardless of the carbon concentration in the samples. In previous reports ${ }^{4}$ concerning pure silicon particles, it was already established by IR measurements that there was a predominance of $\mathrm{SiH}_{2}$ and/or polymeric groups $\left(\mathrm{SiH}_{2}\right)_{n}$, both of them at $2100 \mathrm{~cm}^{-1}$, over the monohydride species that appears at around $2040 \mathrm{~cm}^{-1}$. Nevertheless, in



FIG. 7. IR absorption spectra of the first series of $a-\mathrm{Si}_{1-x} \mathrm{C}_{x}: \mathrm{H}$ powder samples in the range between 450 and $1450 \mathrm{~cm}^{-1}$.



FIG. 8. Raman spectra for $a-\mathrm{Si}_{1-x} \mathrm{C}_{x}: \mathrm{H}$ powder samples of the second series, produced in (a) a gas mixture of $\mathrm{R}=0.4$; (b) the same for $\mathrm{R}=0.6$; (c) after thermal annealing of sample with $\mathrm{R}=0.6\left(800^{\circ} \mathrm{C}\right.$ for $\left.5 \mathrm{~min}\right)$.

the $a-\mathrm{Si}_{1-x} \mathrm{C}_{x}: \mathrm{H}$ powders described here, the samples with low silicon content do not exhibit dihydride related absorptions (bending modes at $800-900 \mathrm{~cm}^{-1}$ are not observed) whereas the absorption near $2100 \mathrm{~cm}^{-1}$ is still present. Therefore, the peak at $2100 \mathrm{~cm}^{-1}$ should be understood as a consequence of (i) the predominance of dihydride arrangements at low carbon contents, and (ii) as carbon concentration increases the total amount of hydrogen bonded to silicon diminishes (Fig. 5), the monohydride $\mathrm{Si}-\mathrm{H}$ remaining (Fig. 6); furthermore, the stretching band of $\mathrm{Si}-\mathrm{H}$ appears at 2100 $\mathrm{cm}^{-1}$ as a consequence of the energy shift of the $\mathrm{Si}-\mathrm{H}$ bond to higher wave numbers caused by the presence of carbon atoms bonded to the vibrating group. ${ }^{18-20}$

The stretching modes of carbon-hydrogen bonds (between 2875 and $\left.2955 \mathrm{~cm}^{-1}\right)^{18}$ do not appear for low carbon concentrations $(\mathrm{R}>0.25)$. For $\mathrm{R}$ lower than 0.55 , both $\mathrm{CH}_{2}$ and $\mathrm{CH}_{3}$ radicals contributed to the $2875 \mathrm{~cm}^{-1}$ peak, whereas the $2930 \mathrm{~cm}^{-1}$ peak is caused by the $\mathrm{CH}_{2}$ radical and that of $2955 \mathrm{~cm}^{-1}$ is caused by the $\mathrm{CH}_{3}$ one. ${ }^{18}$ For $\mathrm{R}<0.55$, carbon-hydrogen bonds are also present in the absorption doublet at $1400 \mathrm{~cm}^{-1}$.

In the range between 700 and $1100 \mathrm{~cm}^{-1}$ there are several absorption peaks that overlap the silicon-hydrogen wagging and bending modes. There is a peak at about $780 \mathrm{~cm}^{-1}$ that Wieder et al. ${ }^{18}$ assigned to $\mathrm{SiCH}_{3}$ wagging modes, whereas other authors ascribed it to the $\mathrm{Si}-\mathrm{C}$ bond. ${ }^{21}$ The band at around $1000 \mathrm{~cm}^{-1}$ may be caused by the wagging vibrations of $\mathrm{CH}_{n}$ bonds in $\mathrm{Si}-\mathrm{CH}_{n}$ groups or/and by oxygen-silicon bonds. An absorption band at $1250 \mathrm{~cm}^{-1}$, attributed to a $\mathrm{C}-\mathrm{C}\left(s p^{3}\right)$ bond, is gradually evidenced as the carbon concentration increases. In addition, the surface oxidation also contributed to the band close to $1000 \mathrm{~cm}^{-1}$.

Figures 8(a) and 8(b) show the Raman spectrum of $a-\mathrm{Si}_{1-x} \mathrm{C}_{x}: \mathrm{H}$ samples obtained in a discharge with gas mixtures of $\mathrm{R}=0.4$ and $\mathrm{R}=0.6$, respectively. The signal was very weak because of the amorphous character of the sample, its 
low density, and the very low scattering cross section and low absorption coefficient in the amorphous state of $\mathrm{Si}-\mathrm{C}$ bonds and $\left(s p^{3}\right) \mathrm{C}-\mathrm{C}$ bonds. ${ }^{22}$ The spectrum of Fig. 8(b) clearly evidences the typical features of hydrogenated amorphous silicon thin films, ${ }^{23}$ i.e., a broad TO-like band close to $480 \mathrm{~cm}^{-1}$, and the shoulder on the low-energy tail of TO band assigned to LA- and LO-like bands. Besides the intrinsic Si-Si vibrations, a band near $1350 \mathrm{~cm}^{-1}$ can be assigned to diamondlike $\left(s p^{3}\right) \mathrm{C}-\mathrm{C}$ bonds, whereas the narrow peaks at around $850-920 \mathrm{~cm}^{-1}$ and $1250-1280 \mathrm{~cm}^{-1}$ are originated by optical activity induced by the $488 \mathrm{~mm}$ laser $\mathrm{Ar}$ line. No graphitelike carbon was found, although it has a high scattering cross section and a high absorption coefficient. The spectrum changed radically after the TDSH experiment, as shown in Fig. 8(c). In addition to polycrystalline silicon features (peak at $520 \mathrm{~cm}^{-1}$ ), ${ }^{23}$ a new broad peak centered at about $900 \mathrm{~cm}^{-1}$ indicated the formation of hexagonal $\mathrm{SiC}^{24}$

\section{CONCLUSION}

Powders of silicon-carbon alloys, $a-\mathrm{Si}_{1-x} \mathrm{C}_{x}: \mathrm{H}$, were produced in a PECVD reactor using various mixtures of silane and methane at low pressure (40-80 $\mathrm{Pa}$ ) and low frequency square-wave modulated $\mathrm{rf}$ power $(13.56 \mathrm{MHz})$.

For all the samples obtained, the hydrogen atom concentration is near $50 \%$. It has been shown that, during the first milliseconds of the discharge, there is an electron loss because of the formation of anions and particle charging. The dependence of the electron density transient behavior on silane concentration in the discharge indicated that silicon species play a crucial role on the powder formation and growth. The particles obtained are less than $100 \mathrm{~nm}$ in diameter and are highly agglomerated. The correspondence between the optical gap energy and powder composition has been estimated. In $a-\mathrm{Si}_{1-x} \mathrm{C}_{x}: \mathrm{H}$ powders, the calculated energy gap is larger than that of thin films with the same composition, probably due to the quantum confinement in the smallest particles. The hydrogen atoms are preferentially bonded to carbon atoms rather than to silicon ones. These powders present two thermal hydrogen evolutions: that observed at low temperature was associated with silicon-hydrogen groups, and that of high temperature with carbon-hydrogen groups.

\section{ACKNOWLEDGMENTS}

This work was supported by the European Community (EC) BRITE-EURAM Program, under Contract No. BRE2CT94-0944, and by a C.I.C.Y.T. project (MAT 1511/94-CE). One of the authors (R. Q. Z.) acknowledges the support from D.G.I.C.Y.T., Programa Nacional F.P.I.

\footnotetext{
${ }^{1}$ J. Vac. Sci. Technol. A 11, 119 (1994).

${ }^{2}$ Plasma Sources Sci. Technol. 3 (1994).

${ }^{3}$ E. Bertran, J. Costa, G. Sardin, J. Campmany, J. L. Andújar, and A. Canillas, Plasma Sources Sci. Technol. 3, 348 (1994).

${ }^{4}$ J. Costa, G. Sardin, J. Campmany, J. L. Andújar, A. Canillas, and E. Bertran, Mater. Res. Soc. Symp. Proc. 297, 1031 (1993)

${ }^{5}$ J. Costa, P. Roura, G. Sardin, J. R. Morante, and E. Bertran, Appl. Phys. Lett. 64, 463 (1994).

${ }^{6}$ J. Costa, P. Roura, A. Canillas, E. Pascual, J. R. Morante, and E. Bertran, Thin Solid Films (in press).

${ }^{7}$ R. A. Andrievski, J. Mater. Sci. 29, 614 (1994).

${ }^{8}$ Y. Watanabe, M. Shiratani, Y. Kubo, I. Ogawa, and S. Ogi, Appl. Phys. Lett. 53, 1263 (1988).

${ }^{9}$ J. T. Verdeyen, J. Beberman, and L. J. Overzet, J. Vac. Sci. Technol. A 8, 1851 (1990).

${ }^{10}$ A. A. Howling, L. Sansonnens, J.-L. Dorier, and Ch. Hollenstein, J. Phys. D 26, 1003 (1993).

${ }^{11}$ A. Lloret, E. Bertran, J. L. Andújar, A. Canillas, and J. L. Morenza, J. Appl. Phys. 69, 632 (1991).

${ }^{12}$ J. L. Andújar, E. Bertran, A. Canillas, J. Campmany, J. Serra, C. Roch, and A. Lloret, J. Appl. Phys. 71, 1546 (1991).

${ }^{13}$ J. L. Andújar, E. Bertran, A. Canillas, J. Esteve, J. Andreu, and J. L. Morenza, Vacuum 39, 795 (1989).

${ }^{14}$ C. M. Horwitz, J. Vac. Sci. Technol. A 1, 1795 (1983).

${ }^{15}$ G. Bruno, P. Capezzuto, and G. Cicala, J. Appl. Phys. 69, 7256 (1991).

${ }^{16}$ J. Tauc, R. Grigorovici, and A. Vancu, Phys. Status Solidi 15, 627 (1966).

${ }^{17}$ D. M. Bhusari and S. T. Kshirsagar, J. Appl. Phys. 73, 1743 (1993).

${ }^{18}$ H. Wieder, M. Cardona, and R. C. Guarnieri, Phys. Status Solidi 92, 99 (1979).

${ }^{19}$ G. Lucovsky, Solid State Commun. 29, 571 (1979).

${ }^{20}$ W. Beyer and H. Mell, in Disorder Semiconductor, edited by M. A. Castner, G. A. Thomas, and S. R. Ovshinky (Plenum, New York, 1987), p. 641.

${ }^{21}$ Y. Catherine and G. Turban, Thin Solid Films 70, 101 (1980).

${ }^{22}$ Y. Inoue, S. Nakashima, A. Mitsuishi, S. Tabata, and S. Tsuboi, Solid State Commun. 48, 1071 (1983).

${ }^{23}$ A. Zwick and R. Carles, Phys. Rev. B 48, 6024 (1993).

${ }^{24}$ P. V. Huong, Diamond Relat. Mater. 1, 33 (1991).
} 